OPEN ACCESS

Edited by: Xavier Figueroa,

Pontificia Universidad Católica de Chile, Chile

Reviewed by: Juan C. Saez,

Pontificia Universidad Católica de Chile, Chile Brant Isakson,

University of Virginia, United States

*Correspondence: Kristin Pogoda

kristin.pogoda@med.uni-augsburg.de

Specialty section:

This article was submitted to

Vascular Physiology,

a section of the journal

Frontiers in Physiology

Received: 12 August 2020 Accepted: 08 October 2020 Published: 29 October 2020

Citation:

Kameritsch $P$ and Pogoda $K$ (2020) The Role of Connexin 43 and Pannexin 1 During Acute Inflammation.

Front. Physiol. 11:594097. doi: 10.3389/fphys.2020.594097

\section{The Role of Connexin 43 and Pannexin 1 During Acute Inflammation}

\author{
Petra Kameritsch ${ }^{1,2}$ and Kristin Pogoda ${ }^{3 *}$ \\ ${ }^{1}$ Institute of Cardiovascular Physiology and Pathophysiology, Biomedical Center, Ludwig-Maximilians-University Munich, \\ Munich, Germany, ${ }^{2}$ Walter Brendel Center of Experimental Medicine, University Hospital, Ludwig-Maximilians-University \\ Munich, Munich, Germany, ${ }^{3}$ Medical Faculty, Department of Physiology, Augsburg University, Augsburg, Germany
}

During acute inflammation, the recruitment of leukocytes from the blood stream into the inflamed tissue is a well-described mechanism encompassing the interaction of endothelial cells with leukocytes allowing leukocytes to reach the site of tissue injury or infection where they can fulfill their function such as phagocytosis. This process requires a fine-tuned regulation of a plethora of signaling cascades, which are still incompletely understood. Here, connexin 43 (Cx43) and pannexin 1 (Panx1) are known to be pivotal for the correct communication of endothelial cells with leukocytes. Pharmacological as well as genetic approaches provide evidence that endothelial Cx43-hemichannels and Panx1-channels release signaling molecules including ATP and thereby regulate vessel function and permeability as well as the recruitment of leukocytes during acute inflammation. Furthermore, Cx43 hemichannels and Panx1-channels in leukocytes release signaling molecules and can mediate the activation and function of leukocytes in an autocrine manner. The focus of the present review is to summarize the current knowledge of the role of $\mathrm{Cx} 43$ and Panx1 in endothelial cells and leukocytes in the vasculature during acute inflammation and to discuss relevant molecular mechanisms regulating $\mathrm{Cx} 43$ and Panx1 function.

Keywords: hemichannel, leukocyte, connexin, gap junction, acute inflammation, endothelial cells, ATP

\section{INTRODUCTION}

During acute inflammation the recruitment of leukocytes from the bloodstream to the site of injury or infection is a highly regulated mechanism to ensure that leukocytes leave the bloodstream specifically at the inflammatory site to eliminate the inflammatory trigger (Nourshargh and Alon, 2014). In a series of different consecutive steps including rolling, adhesion processes, crawling, and transmigration through the microvascular endothelial layer leukocytes are in close contact to the endothelium (Nourshargh and Alon, 2014). For a correct regulation of these events during the recruitment cascade, the interaction and communication between leukocytes and endothelial cells (EC) but also between leukocytes or between EC are of particular importance.

Gap junction channels (GJ) are formed by two hemichannels, composed of six connexin (Cx) proteins, and allow the direct transfer of molecules between adjacent cells in a tissue (Kumar and Gilula, 1996). Cx-hemichannels can act as a transmembrane conduit between the cytoplasm and 
the extracellular space to release paracrine or autocrine signaling molecules (Bruzzone et al., 2001; De Vuyst et al., 2007; Willebrords et al., 2016). Under physiological conditions they are normally closed but open with injury and inflammation and can induce cytokine release (Cheng et al., 2014). Pannexins (Panx) form functional membrane channels and are like Cxhemichannels and GJ permeable to small molecules including ATP, ions or metabolites (Bruzzone et al., 2003; Zhou et al., 2019). Panx mediated ATP-release has been implicated in inflammatory responses of several immune cells (Lohman et al., 2015; Zhou et al., 2019). Cx and Panx are widely expressed in immune cells and are critically involved in immune cell functions and the regulation of inflammatory responses (Oviedo-Orta and Howard Evans, 2004; Glass et al., 2015; Esseltine and Laird, 2016; Aasen et al., 2019). Among them connexin 43 (Cx43) and pannexin 1 (Panx1) are present in all immune cells and the most studied isoforms (Esseltine and Laird, 2016; Valdebenito et al., 2018; Wang and Chen, 2018). In this mini review we will address the role of Cx43-hemichannels, Panx1-channels as well the intercellular communication via GJ in EC and leukocytes during acute inflammation.

\section{IMPACT OF Panx1 AND Cx43 FOR COMMUNICATION OF EC AND DIFFERENT TYPES OF LEUKOCYTES (SEE FIGURE 1)}

Intercellular communication between various cells of the immune system has been described for many years (Hulser and Peters, 1972) and in the last decades the expression pattern of $\mathrm{Cx}$ as well as the coupling between immune cells or with EC was analyzed. Also the role of endothelial $\mathrm{Cx} / \mathrm{GJ}$ for the behavior of leukocytes was focus of many studies (Oviedo-Orta and Howard Evans, 2004; Okamoto and Suzuki, 2017). Intercellular coupling between lymphocytes expressing Cx40 and Cx43 (Oviedo-Orta et al., 2000) was involved in the proliferation of T-cell subsets (Zhang et al., 2018) and lymphocyte-macrophagecoupling (Bermudez-Fajardo et al., 2007). Other leukocytes like neutrophils express various $\mathrm{Cx}$, among them Cx43 (Jara et al., 1995) and are able to form functional GJ among themselves (Branes et al., 2002).

Also direct or indirect communication of leukocytes with other cell types like endothelial (Zahler et al., 2003), epithelial (Pepin et al., 2020), or cancer cells (Hofmann et al., 2019) has been detected. Zahler et al. (2003) analyzed neutrophils that were able to exchange a GJ permeable dye with EC and Sarieddine et al. (2009) could demonstrate that adhesion of neutrophils was regulated by gap junctional coupling via Cx43 with endothelial (and epithelial) cells in the lung. Direct communication between lymphocytes is suggested to play a role in T-lymphocyte proliferation contributing to hypertensive inflammatory response (Ni et al., 2017) and GJ between cytotoxic T-lymphocytes and cancer cells allowed the immune system to control cancer cells (Hofmann et al., 2019). Furthermore, Cx43 expression and GJ communication were shown to be transiently induced between monocytes/macrophages at inflammatory sites (Eugenin et al., 2003) and macrophages were shown to communicate via GJ with epithelial cells thereby amplifying the antiviral response (Pepin et al., 2020).

Li et al. (2019) confirmed the role of $\mathrm{Cx} 43$ in promoting the adhesion of monocytes to EC. In contrast to others, the authors did not find any adhesive effects of the GJ but could show that enhanced expression of $\mathrm{Cx} 43$ in EC led to activation of the PI3K/AKT/NF- $\kappa \mathrm{B}$ signaling pathway finally enhancing VCAM-1 and ICAM-1 expression and thereby increasing monocyte-endothelial adhesion. This effect seems to be prominent in EC exposed to high blood pressure leading to an enhanced expression of $\mathrm{Cx} 43$ and therefore to an enhanced monocyte-endothelial adhesion. Furthermore, Cx43 expression in monocytes also affects monocyte-endothelial adhesion (Ji et al., 2019) as inhibition of Cx43 expression in monocytes led to a decreased activity of the PI3K/AKT/NF- $\kappa \mathrm{B}$ signaling pathway resulting in a decreased monocyte-endothelial adhesion, finally offering new thoughts for understanding atherosclerosis. The release of IL-17 from lymphocytes led to a decrease of Cx43 expression in limbal vascular EC (Qin et al., 2019) indicating an indirect communication of lymphocytes with EC.

Panx can similar to $\mathrm{Cx}$ act as hemichannels and were described to be able to form intercellular channels (Bruzzone et al., 2003; Sohl et al., 2005). However, most publications describe their function as hemichannels (Lohman et al., 2015) suggesting an indirect coupling of cells via the release of signaling molecules affecting regulatory processes of effector cells. Panx expression in EC and during inflammation has been reviewed recently (Begandt et al., 2017) and although Panx are known to be important in this context, their regulation in inflammation is unclear (Begandt et al., 2017). However, post-translational modifications of Panx1 (phosphorylation, S-nitrosylation, or caspase cleavage) can affect channel properties (Boyce et al., 2018). As demonstrated in smooth muscle cells a direct Src-dependent phosphorylation at Tyr198 within a Src homology 2 (SH2) domain in the intracellular loop seems to be involved in Panx1-dependent regulation of adrenergic mediated vasoconstriction (Delalio et al., 2019). Moreover, it was shown that spironolactone, an anti-hypertensive drug, inhibits the permeability of Panx1-channels thereby regulating $\alpha$-adrenergic vasoconstriction (Good et al., 2018).

Under ischemic (Kaneko et al., 2015) or pro-inflammatory (Lohman et al., 2015) conditions, the latter only in venous but not arterial EC, the permeability of endothelial Panx1-channels was increased leading to decreased leukocyte adhesion (Lohman et al., 2015). Furthermore, the opening of Panxl seems to be involved in ischemia/reperfusion injury-induced inflammation in the brain (Thuringer et al., 2015; Wei et al., 2015) and the lung increasing next to others vascular permeability and neutrophil infiltration (Sharma et al., 2018). Other inflammatory mediators like thrombin or histamine also led to an increased permeability of Panx1 whereas Cx43-hemichannel activity was reduced in this context (Godecke et al., 2012). Next to EC, Panx have also been shown to be expressed in leukocytes (Schenk et al., 2008; Woehrle et al., 2010; Li et al., 2018) and their expression was upregulated due to infection (Li et al., 2018). However, not only the expression 


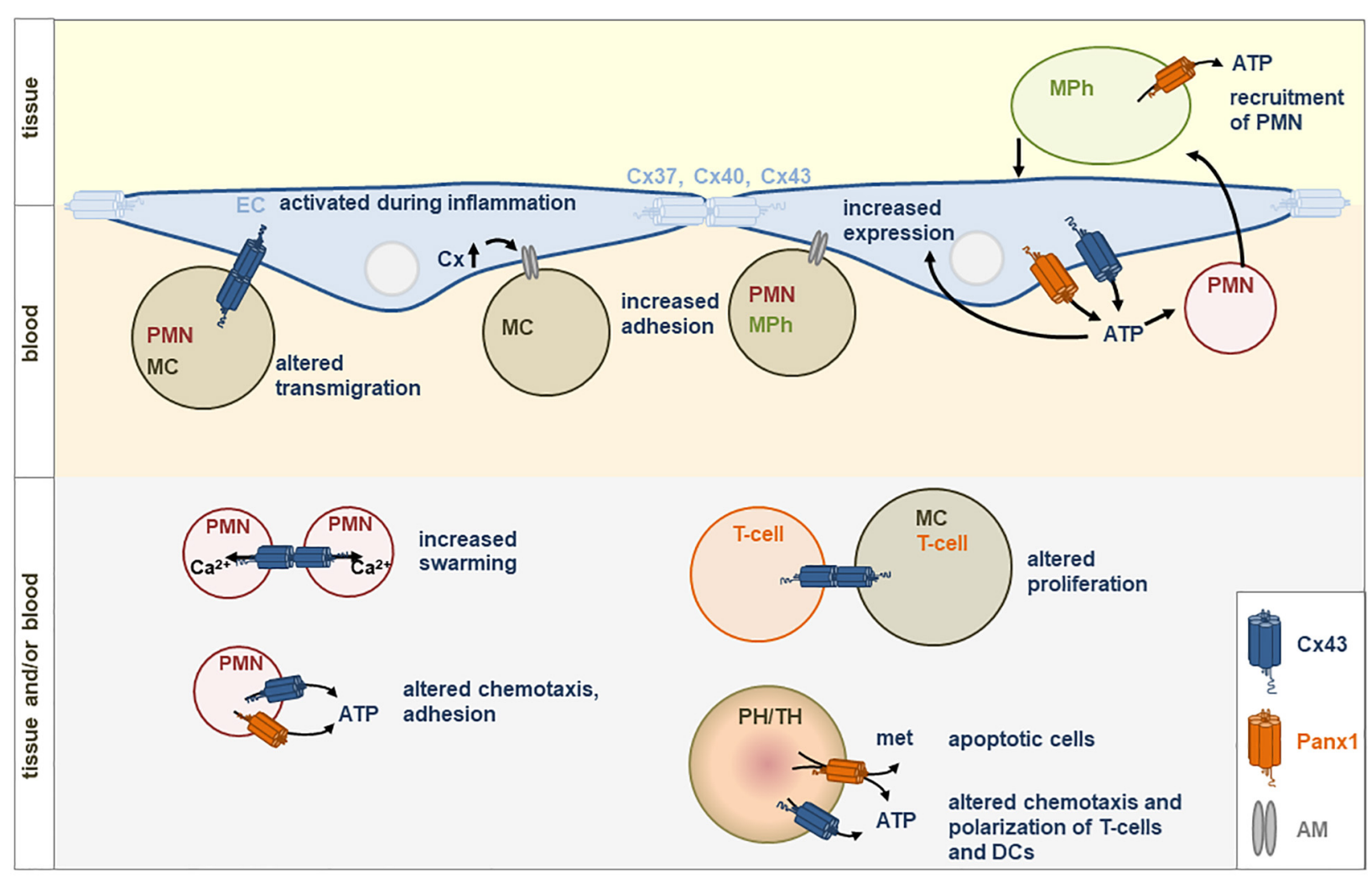

FIGURE 1 | Direct (gap junctions) or indirect (via hemichannels) communication between immune cells (PH, phagocytes; TH, thymocytes; PMN, neutrophils; MC, monocytes; MPh, macrophages) or with endothelial cells $(E C)$ is involved in immune responses. Gap junctions are built by connexins (Cx). Hemichannels can be formed by Cx43 or Panx1. met, metabolites; PIH, pregnancy induced hypertension; AM, adhesion molecules; ATP, Adenosine triphosphate.

was upregulated but also its distribution pattern within the cell changed due to activation of the immune system. In primary T-cells Panx1 was distributed homogenously via the cell surface and translocated rapidly to the immune synapse after stimulation of the cells (Woehrle et al., 2010).

\section{CX43 IN LEUKOCYTE RECRUITMENT DURING ACUTE INFLAMMATION}

Leukocyte recruitment during acute inflammation seems to be highly reliant on endothelial $\mathrm{Cx} 43$. TNF $\alpha$-induced leukocyte adhesion and transmigration in vivo were reduced in endothelial Cx43-deficient mice as well as in the presence of GJ blockers in wild-type animals (Veliz et al., 2008). In a model of acute lung injury Cx43 was markedly enhanced in the lung of mice subjected to instillation with LPS and neutrophil recruitment was upregulated in homozygous $\mathrm{Cx} 43^{+/+}$compared to heterozygous $\mathrm{Cx}_{4} 3^{ \pm}$mice (Sarieddine et al., 2009). In vitro studies confirmed a reduced adhesion of activated neutrophils to EC or alveolar epithelial cells with blocked Cx43-containing GJ, which are both involved in LPS-induced lung inflammation. In contrast, incubation of GJ-blocked neutrophils with untreated EC did not reduce the number of adherent neutrophils (Sarieddine et al., 2009) indicating that a signal transfer between endothelial or epithelial cells via Cx43-containing GJ significantly contributes to neutrophil recruitment during acute inflammation. In contrast, Cx40 expression is downregulated during acute lung injury and endothelial-specific deletion of $\mathrm{Cx} 40$ resulted in increased transmigration of neutrophils after intratracheal instillation of LPS. Downregulation of $\mathrm{Cx} 40$ in $\mathrm{EC}$ in vitro, which was accompanied by a decreased expression and activity of CD73, increased adhesion of neutrophils to the endothelial monolayer suggesting an anti-inflammatory protective role in contrast to Cx43 (Chadjichristos et al., 2010; Scheckenbach et al., 2011). In another study it was shown that treatment of EC with peptidoglycan, a gram-positive bacterial cell wall component, induced ATP-release via Cx43-hemichannel opening which elicited a pro-inflammatory response by induction of interleukin 6 and Toll-like receptor 2 expression (Robertson et al., 2010), both known to be involved in leukocyte recruitment (Jones, 2005; Sabroe et al., 2005).

In neutrophils, $\mathrm{Cx} 43$ is primarily involved in ATP-release via hemichannels (Eltzschig et al., 2006). Dependent on the extracellular ATP concentration different functions like chemotaxis or adhesion are affected by different purinergic receptors (Trautmann, 2009; Wang and Chen, 2018). The ATP-release via Cx43-hemichannels from activated neutrophils during acute inflammation may have endothelial barrier protective and anti-inflammatory effects (Eltzschig et al., 2006). 
Phosphorylation of $\mathrm{Cx} 43$ at Ser368 is associated with reduced opening (Bao et al., 2004) and ATP-release of activated neutrophils is regulated by Ser368 de-phosphorylation via phosphatase A. This phosphorylation-dependent ATP-release decreased endothelial paracellular permeability by modulating endothelial adenosine responses and might serve as a stopping signal for neutrophil chemotaxis (Eltzschig et al., 2006) to halt their migration at the infectious site. Moreover, it has been shown that LPS-induced autocrine ATP signaling inhibited neutrophil chemotaxis and knockout of the ATP receptor (P2X1) in neutrophil-like differentiated HL-60 cells recovered chemotaxis (Wang et al., 2017). LPS-induced ATP-release through $\mathrm{Cx} 43$-hemichannels of activated neutrophils induced a calcium ion $\left(\mathrm{Ca}^{2+}\right)$ influx via $\mathrm{P} 2 \mathrm{X} 1$ receptors, a ligandgated cation channel with high $\mathrm{Ca}^{2+}$ permeability, which reduced neutrophil chemotaxis by activating myosin light chain phosphorylation (Wang et al., 2017). Of note, degranulation and phagocytosis were enhanced by autocrine ATP-release. Hence, activated neutrophils release ATP to stop chemotaxis which might therefore facilitate the bactericidal functions of neutrophils (Wang et al., 2017). Moreover, neutrophil Cx43 has been shown to be crucial for coordinated $\mathrm{Ca}^{2+}$ fluxes and initiation of the neutrophil swarming (Poplimont et al., 2020). The first step, the initial recruitment of neutrophils to the site of inflammation is induced by damage-associated molecular patterns (DAMPs) from damaged or dead cells and pathogen-associated molecular patterns (PAMPs) released by invading microorganisms, causing the release of chemoattractants by local tissue cells. In contrast, the second step, the highly coordinated neutrophil movement with dense clusters and swarm aggregation at the wound core is mediated by paracrine release of the chemoattractant leukotriene B4 (LTB4), whose synthesis requires a sustained $\mathrm{Ca}^{2+}$ flux (Kienle and Lammermann, 2016; Poplimont et al., 2020). Cx43dependent ATP-release via hemichannels induced calcium signal propagation in clustering neutrophils leading to LTB4 biosynthesis in neutrophils in a zebrafish model (Poplimont et al., 2020). The authors conclude that hemichannel opening of pioneer neutrophils upon contact with death-specific signals such as fMLP mediate $\mathrm{Ca}^{2+}$ flux-dependent LTB4-release, activating a secondary $\mathrm{Cx} 43$-channel opening leading to sustained intracluster $\mathrm{Ca}^{2+}$ fluxes (Poplimont et al., 2020). This study indicates that $\mathrm{Cx} 43$-channels play a crucial role for neutrophil swarm generation and chemoattractant production during acute inflammation.

The motility and transendothelial migration of B-cells also depend on Cx43 and are decreased after downregulation, likely regulated channel-independently by $\mathrm{Cx} 43$ (Machtaler et al., 2014), indicating that Cx43 can affect the individual steps of leukocyte recruitment via different mechanisms.

\section{Panx1 IN LEUKOCYTE RECRUITMENT DURING ACUTE INFLAMMATION}

Panx can be considered as key upstream molecules in inflammasome activation (Pelegrin and Surprenant, 2006) and several studies have shown that ATP-release through Panx1channels enhances inflammatory responses (Adamson and Leitinger, 2014). The progressive opening of Panx1-channels in response to inflammatory stimuli can be activated by a caspasedependent cleavage of the C-terminal tail controlling channel permeability (Makarenkova et al., 2018; Chen et al., 2019) associated with NLRP3 inflammasome activation in apoptotic macrophages (Chen et al., 2020). Moreover, Panx1 promotes recognition of bacterial molecules to activate the cryopyrin inflammasome (Kanneganti et al., 2007). The interaction of Panx with $\mathrm{P} 2 \mathrm{X}_{7}$ receptors has been reported to create a large permeable pore at the cell membrane and ATP-mediated activation of the inflammasome promotes the secretion of cytokines (Adamson and Leitinger, 2014). The release of ATP via Panx1-channels is involved in leukocytes recruitment by guiding chemotaxis of neutrophils and macrophages via purinergic receptor signaling activated by extracellular ATP (Adamson and Leitinger, 2014). Studies on neutrophil migration showed that ATP-release via Panx1-channels plays a dual role to trigger signals: excitatory signals by amplifying chemotactic signals and facilitating gradient sensing at the front of polarized neutrophils and inhibitory signals via $\mathrm{A}_{2 \mathrm{~A}}$ adenosine receptors involved in blocking chemoattractant receptor signaling at the back of migrating neutrophils, demonstrating the role of Panx1 as fine-tune regulator of chemotactic responses of neutrophils (Chen et al., 2006, 2010; Bao et al., 2013). The ATP-release via Panx1-channels and autocrine stimulation of $\mathrm{P}_{2} \mathrm{X}_{4}$ receptors also contributes to T-cell polarization and migration, whereas blocking of $\mathrm{P}_{2} \mathrm{X}_{4}$ receptors inhibited $\mathrm{T}$-cell activation and migration in vitro (Ledderose et al., 2018). ATP-release via Panx1 is also required for secretion of IL- $1 \beta$ from macrophages induced by $\mathrm{P}_{2} \mathrm{X}_{7}$ receptor activation (Pelegrin and Surprenant, 2006). In dendritic cells extracellular ATP stimulated fast cell migration through an autocrine signaling loop initiated by $\mathrm{P}_{2} \mathrm{X}_{7}$ receptor activation and amplified by opening of Panx1-channels and supplementary release of ATP (Saez et al., 2017).

The extravasation of leukocytes across the vascular wall to the site of injury is dependent on Panx1-mediated ATP-release from venous endothelium (Lohman et al., 2015). Stimulation of venous EC with TNF $\alpha$ induced expression and activation of Panx1-channels stimulating $\mathrm{Ca}^{2+}$-dependent synthesis of IL-1 $\beta$ (Yang et al., 2020) and ATP-release inducing leukocyte adhesion and emigration in vitro and in vivo (Lohman et al., 2015). The latter might be partially mediated by increased endothelial expression of the adhesion molecule VCAM-1 (Dosch et al., 2018). Notably, EC derived nitric oxide can inhibit Panx1 activity through S-nitrosylation which reduces ATP-release and Panx1channel currents in murine EC (Lohman et al., 2012).

Recently, Tam et al. (2020) demonstrated that during metabolic inflammation pro-inflammatory macrophages release chemotactic factors upon exposure to saturated fatty acids, such as palmitate, which was associated with recruitment and infiltration of neutrophils into adipose tissues. Heat inactivation or proteinase $\mathrm{K}$ digestion of media released by fatty acid treated macrophages did not alter neutrophil recruitment but was effective to inhibit CXCL-1 induced chemotaxis suggesting that these macrophage derived chemotactic factors are not 
proteins (Tam et al., 2020). Moreover, the authors found that palmitate upregulated Panx1-channel expression in macrophages mediating neutrophil attraction by release of nucleotides such as ATP. The thereby following purinergic receptor stimulation and signaling induces neutrophil migration (Tam et al., 2020). These results emphasize the role of Panx1 in neutrophil recruitment and its contribution to inflammatory response during obesity. The impact of Panx1 for leukocyte recruitment during inflammation has also been demonstrated using a pharmacologic blocking of Panx1-channels by trovafloxacin, which decreased ICAM1 expression and delayed recruitment of monocytes and neutrophils (Giustarini et al., 2019).

Due to the fact that Panx1-channels also regulate host responses to viruses (Orellana et al., 2013; Malik and Eugenin, 2019) the impact of Panx1 in COVID19 patients displaying hyper-inflammation has recently been discussed (Swayne et al., 2020). For the patient recovery especially the early phase of innate immunity seems to be critical and immunosuppression could limit viral entry and disease progression. Therefore, targeting Panx1-channels could improve therapeutic approaches and might reduce SARS-CoV-2 infectivity and vascular inflammatory responses in COVID19 patients (Swayne et al., 2020).

\section{MOLECULES TRANSMITTED VIA Panx1-CHANNELS AND CX43-CHANNELS}

There are many data about the release of ATP via Cx43- or Panx1-channels: neutrophils for example are known to release ATP via Cx43-hemichannels during hypoxia or inflammation (Eltzschig et al., 2008). In inflamed lung EC, the release of ATP was shown to be mediated via Panxl (Sharma et al., 2018) and in a fish model tPanx1-channels in leukocytes and other cells were responsible for the release of ATP (Li et al., 2018). In smooth muscle cells Panx1 mediated ATP-release is regulated by a direct Src-dependent phosphorylation at Tyr198 (Delalio et al., 2019) and purinergic regulation of migrating T-cells was shown to be stimulated by an ATP-release via Panx1 (Ledderose et al., 2018). For intercellular communication via GJ, it is common knowledge that molecules up to a size of $1.8 \mathrm{kD}$ can be transferred between cells (Neijssen et al., 2005). Typically, ions like $\mathrm{K}^{+}$or $\mathrm{Ca}^{2+}$ and second messengers like cAMP were shown to diffuse from one cell to the other

\section{REFERENCES}

Aasen, T., Leithe, E., Graham, S. V., Kameritsch, P., Mayan, M. D., Mesnil, M., et al. (2019). Connexins in cancer: bridging the gap to the clinic. Oncogene 38, 4429-4451. doi: 10.1038/s41388-019-0741-6

Adamson, S. E., and Leitinger, N. (2014). The role of pannexin1 in the induction and resolution of inflammation. FEBS Lett. 588, 1416-1422. doi: 10.1016/j. febslet.2014.03.009

Bao, X., Altenberg, G. A., and Reuss, L. (2004). Mechanism of regulation of the gap junction protein connexin 43 by protein kinase C-mediated phosphorylation. Am. J. Physiol. Cell Physiol. 286, C647-C654. doi: 10.1152/ajpcell.00295.2003

Bao, Y., Chen, Y., Ledderose, C., Li, L., and Junger, W. G. (2013). Pannexin 1 channels link chemoattractant receptor signaling to local excitation and global
(Valiunas et al., 2019) but for the communication between either immune cells or between immune and endothelial/epithelial cells less data are available. Zhang et al. speculated that ATP diffuses via GJ between lymphocytes (Zhang et al., 2018). For cytotoxic T-cells that form GJ with cancer cells leading to an enhanced granzyme $\mathrm{B}$ activity in cancer cells it was thought that granzyme $\mathrm{B}$ or $\mathrm{Ca}^{2+}$ may be transferred (Hofmann et al., 2019) and macrophages that communicate via GJ with epithelial cells (Pepin et al., 2020) seem to mediate cGAMP via intercellular channels. Also peptides have been shown to be transferred via GJ between cells causing recognition of nearby bystander cells and activated monocytes by cytotoxic T-cells (Neijssen et al., 2005).

\section{DISCUSSION}

The activity of both Cx43-hemichannels and Panx1-channels depends on diverse environmental stimuli and increases under pathophysiological conditions including acute inflammation. Their opening allows the release of signaling molecules from the cytoplasm acting as autocrine or paracrine messengers (Evans et al., 2006) and enables activated EC and leukocytes to finetune responses during acute inflammation. Most of the described effects of inflammatory cells are mediated via ATP-release through Cx43-hemichannels or Panx1-channels and purinergic receptor signaling but also the gap junctional transfer of signaling molecules affects the recruitment of leukocytes. Despite the increasing amount of studies on $\mathrm{Cx}$ - and Panx-functions in EC and leukocytes still little is known about their interplay and regulation during acute and chronic inflammation and requires further investigations. Moreover, it should be mentioned that pharmacologic inhibition of $\mathrm{Cx} 43$-hemichannels at least partly affects Panx1 and GJ and making the discrimination between hemichannels and GJ difficult (Willebrords et al., 2017). However, targeting Panx1- or Cx43-dependent ATP-release and purinergic signaling could represent a promising approach for the therapeutical treatment of acute inflammation.

\section{AUTHOR CONTRIBUTIONS}

PK and KP wrote the manuscript. Both authors contributed to the article and approved the submitted version.

inhibition responses at the front and back of polarized neutrophils. J. Biol. Chem. 288, 22650-22657. doi: 10.1074/jbc.M113.476283

Begandt, D., Good, M. E., Keller, A. S., Delalio, L. J., Rowley, C., Isakson, B. E., et al. (2017). Pannexin channel and connexin hemichannel expression in vascular function and inflammation. BMC Cell Biol. 18:2. doi: 10.1186/s12860-0160119-3

Bermudez-Fajardo, A., Yliharsila, M., Evans, W. H., Newby, A. C., and OviedoOrta, E. (2007). CD4+ T lymphocyte subsets express connexin 43 and establish gap junction channel communication with macrophages in vitro. J. Leukoc. Biol. 82, 608-612. doi: 10.1189/jlb.0307134

Boyce, A. K. J., Epp, A. L., Nagarajan, A., and Swayne, L. A. (2018). Transcriptional and post-translational regulation of pannexins. Biochim. Biophys. Acta Biomembr. 1860, 72-82. doi: 10.1016/j.bbamem.2017.03.004 
Branes, M. C., Contreras, J. E., and Saez, J. C. (2002). Activation of human polymorphonuclear cells induces formation of functional gap junctions and expression of connexins. Med. Sci. Monit. 8, BR313-BR323.

Bruzzone, R., Hormuzdi, S. G., Barbe, M. T., Herb, A., and Monyer, H. (2003). Pannexins, a family of gap junction proteins expressed in brain. Proc. Natl. Acad. Sci. U.S.A. 100, 13644-13649. doi: 10.1073/pnas.2233464100

Bruzzone, S., Guida, L., Zocchi, E., Franco, L., and De Flora, A. (2001). Connexin 43 hemi channels mediate $\mathrm{Ca} 2+$-regulated transmembrane NAD+ fluxes in intact cells. FASEB J. 15, 10-12. doi: 10.1096/fj.00-0566fje

Chadjichristos, C. E., Scheckenbach, K. E., Van Veen, T. A., Richani Sarieddine, M. Z., De Wit, C., Yang, Z., et al. (2010). Endothelial-specific deletion of connexin 40 promotes atherosclerosis by increasing CD73-dependent leukocyte adhesion. Circulation 121, 123-131. doi: 10.1161/CIRCULATIONAHA.109. 867176

Chen, K. W., Demarco, B., and Broz, P. (2020). Pannexin-1 promotes NLRP3 activation during apoptosis but is dispensable for canonical or noncanonical inflammasome activation. Eur. J. Immunol. 50, 170-177. doi: 10.1002/eji. 201948254

Chen, W., Zhu, S., Wang, Y., Li, J., Qiang, X., Zhao, X., et al. (2019). Enhanced macrophage Pannexin 1 expression and hemichannel activation exacerbates lethal experimental sepsis. Sci. Rep. 9:160. doi: 10.1038/s41598-01837232-Z

Chen, Y., Corriden, R., Inoue, Y., Yip, L., Hashiguchi, N., Zinkernagel, A., et al. (2006). ATP release guides neutrophil chemotaxis via P2Y2 and A3 receptors. Science 314, 1792-1795. doi: 10.1126/science.1132559

Chen, Y., Yao, Y., Sumi, Y., Li, A., To, U. K., Elkhal, A., et al. (2010). Purinergic signaling: a fundamental mechanism in neutrophil activation. Sci. Signal. 3:ra45. doi: 10.1126/scisignal.2000549

Cheng, R. D., Ren, J. J., Zhang, Y. Y., and Ye, X. M. (2014). P2X4 receptors expressed on microglial cells in post-ischemic inflammation of brain ischemic injury. Neurochem. Int. 67, 9-13. doi: 10.1016/j.neuint.2014.01.011

De Vuyst, E., Decrock, E., De Bock, M., Yamasaki, H., Naus, C. C., Evans, W. H., et al. (2007). Connexin hemichannels and gap junction channels are differentially influenced by lipopolysaccharide and basic fibroblast growth factor. Mol. Biol. Cell 18, 34-46. doi: 10.1091/mbc.e06-03-0182

Delalio, L. J., Billaud, M., Ruddiman, C. A., Johnstone, S. R., Butcher, J. T., Wolpe, A. G., et al. (2019). Constitutive SRC-mediated phosphorylation of pannexin 1 at tyrosine 198 occurs at the plasma membrane. J. Biol. Chem. 294, 6940-6956. doi: $10.1074 /$ jbc.RA118.006982

Dosch, M., Gerber, J., Jebbawi, F., and Beldi, G. (2018). Mechanisms of ATP release by inflammatory cells. Int. J. Mol. Sci. 19:1222. doi: 10.3390/ijms19041222

Eltzschig, H. K., Eckle, T., Mager, A., Kuper, N., Karcher, C., Weissmuller, T., et al. (2006). ATP release from activated neutrophils occurs via connexin 43 and modulates adenosine-dependent endothelial cell function. Circ. Res. 99, 1100-1108. doi: 10.1161/01.RES.0000250174.31269.70

Eltzschig, H. K., Macmanus, C. F., and Colgan, S. P. (2008). Neutrophils as sources of extracellular nucleotides: functional consequences at the vascular interface. Trends Cardiovasc. Med. 18, 103-107. doi: 10.1016/j.tcm.2008.01.006

Esseltine, J. L., and Laird, D. W. (2016). Next-generation connexin and pannexin cell biology. Trends Cell. Biol. 26, 944-955. doi: 10.1016/j.tcb.2016.06.003

Eugenin, E. A., Branes, M. C., Berman, J. W., and Saez, J. C. (2003). TNF-alpha plus IFN-gamma induce connexin 43 expression and formation of gap junctions between human monocytes/macrophages that enhance physiological responses. J. Immunol. 170, 1320-1328. doi: 10.4049/jimmunol.170.3.1320

Evans, W. H., De Vuyst, E., and Leybaert, L. (2006). The gap junction cellular internet: connexin hemichannels enter the signalling limelight. Biochem. J. 397, 1-14. doi: 10.1042/BJ20060175

Giustarini, G., Vrisekoop, N., Kruijssen, L., Wagenaar, L., Van Staveren, S., Van Roest, M., et al. (2019). Trovafloxacin-induced liver injury: lack in regulation of inflammation by inhibition of nucleotide release and neutrophil movement. Toxicol. Sci. 167, 385-396. doi: 10.1093/toxsci/kfy244

Glass, A. M., Snyder, E. G., and Taffet, S. M. (2015). Connexins and pannexins in the immune system and lymphatic organs. Cell Mol. Life Sci. 72, 2899-2910. doi: 10.1007/s00018-015-1966-3

Godecke, S., Roderigo, C., Rose, C. R., Rauch, B. H., Godecke, A., and Schrader, J. (2012). Thrombin-induced ATP release from human umbilical vein endothelial cells. Am. J. Physiol. Cell Physiol. 302, C915-C923. doi: 10.1152/ajpcell. 00283.2010
Good, M. E., Chiu, Y. H., Poon, I. K. H., Medina, C. B., Butcher, J. T., Mendu, S. K., et al. (2018). Pannexin 1 channels as an unexpected new target of the anti-hypertensive drug spironolactone. Circ. Res. 122, 606-615. doi: 10.1161/ CIRCRESAHA.117.312380

Hofmann, F., Navarrete, M., Alvarez, J., Guerrero, I., Gleisner, M. A., Tittarelli, A., et al. (2019). Cx43-Gap junctions accumulate at the cytotoxic immunological synapse enabling Cytotoxic T lymphocyte melanoma cell killing. Int. J. Mol. Sci. 20:4509. doi: 10.3390/ijms20184509

Hulser, D. F., and Peters, J. H. (1972). Contact cooperation in stimulated lymphocytes. II. Electrophysiological investigations on intercellular communication. Exp. Cell Res. 74, 319-326. doi: 10.1016/0014-4827(72) 90383-7

Jara, P. I., Boric, M. P., and Saez, J. C. (1995). Leukocytes express connexin 43 after activation with lipopolysaccharide and appear to form gap junctions with endothelial cells after ischemia-reperfusion. Proc. Natl. Acad. Sci. U.S.A. 92, 7011-7015. doi: 10.1073/pnas.92.15.7011

Ji, H., Qiu, R., Gao, X., Zhang, R., Li, X., Hei, Z., et al. (2019). Propofol attenuates monocyte-endothelial adhesion via modulating connexin 43 expression in monocytes. Life Sci. 232:116624. doi: 10.1016/j.lfs.2019.116624

Jones, S. A. (2005). Directing transition from innate to acquired immunity: defining a role for IL-6. J. Immunol. 175, 3463-3468. doi: 10.4049/jimmunol.175.6.3463

Kaneko, Y., Tachikawa, M., Akaogi, R., Fujimoto, K., Ishibashi, M., Uchida, Y., et al. (2015). Contribution of pannexin 1 and connexin 43 hemichannels to extracellular calcium-dependent transport dynamics in human blood-brain barrier endothelial cells. J. Pharmacol. Exp. Ther. 353, 192-200. doi: 10.1124/ jpet.114.220210

Kanneganti, T. D., Lamkanfi, M., Kim, Y. G., Chen, G., Park, J. H., Franchi, L., et al. (2007). Pannexin-1-mediated recognition of bacterial molecules activates the cryopyrin inflammasome independent of Toll-like receptor signaling. Immunity 26, 433-443. doi: 10.1016/j.immuni.2007.03.008

Kienle, K., and Lammermann, T. (2016). Neutrophil swarming: an essential process of the neutrophil tissue response. Immunol. Rev. 273, 76-93. doi: 10.1111/imr. 12458

Kumar, N. M., and Gilula, N. B. (1996). The gap junction communication channel. Cell 84, 381-388. doi: 10.1016/s0092-8674(00)81282-9

Ledderose, C., Liu, K., Kondo, Y., Slubowski, C. J., Dertnig, T., Denicolo, S., et al. (2018). Purinergic P2X4 receptors and mitochondrial ATP production regulate T cell migration. J. Clin. Invest. 128, 3583-3594. doi: 10.1172/JCI120972

Li, S., Li, J., Wang, N., Zhang, T., Xu, Y., and Sun, J. (2018). Expression analysis of Pannexin1 channel gene in response to immune challenges and its role in infection-induced ATP release in tilapia (Oreochromis niloticus). Fish Shellfish Immunol. 81, 470-475. doi: 10.1016/j.fsi.2018.07.050

Li, X., Zhang, Q., Zhang, R., Cheng, N., Guo, N., Liu, Y., et al. (2019). Downregulation of Cx43 expression on PIH-HUVEC cells attenuates monocyteendothelial adhesion. Thromb. Res. 179, 104-113. doi: 10.1016/j.thromres.2019. 05.009

Lohman, A. W., Leskov, I. L., Butcher, J. T., Johnstone, S. R., Stokes, T. A., Begandt, D., et al. (2015). Pannexin 1 channels regulate leukocyte emigration through the venous endothelium during acute inflammation. Nat. Commun. 6:7965. doi: $10.1038 /$ ncomms 8965

Lohman, A. W., Weaver, J. L., Billaud, M., Sandilos, J. K., Griffiths, R., Straub, A. C., et al. (2012). S-nitrosylation inhibits pannexin 1 channel function. J. Biol. Chem. 287, 39602-39612. doi: 10.1074/jbc.M112.397976

Machtaler, S., Choi, K., Dang-Lawson, M., Falk, L., Pournia, F., Naus, C. C., et al. (2014). The role of the gap junction protein connexin 43 in B lymphocyte motility and migration. FEBS Lett. 588, 1249-1258. doi: 10.1016/j.febslet.2014. 01.027

Makarenkova, H. P., Shah, S. B., and Shestopalov, V. I. (2018). The two faces of pannexins: new roles in inflammation and repair. J. Inflamm. Res. 11, 273-288. doi: $10.2147 / J I R . S 128401$

Malik, S., and Eugenin, E. A. (2019). Role of connexin and pannexin containing channels in HIV infection and NeuroAIDS. Neurosci. Lett. 695, 86-90. doi: 10.1016/j.neulet.2017.09.005

Neijssen, J., Herberts, C., Drijfhout, J. W., Reits, E., Janssen, L., and Neefjes, J. (2005). Cross-presentation by intercellular peptide transfer through gap junctions. Nature 434, 83-88. doi: 10.1038/nature03290

Ni, X., Wang, A., Zhang, L., Shan, L. Y., Zhang, H. C., Li, L., et al. (2017). Upregulation of gap junction in peripheral blood $\mathrm{T}$ lymphocytes contributes to 
the inflammatory response in essential hypertension. PLoS ONE 12:e0184773. doi: 10.1371 /journal.pone. 0184773

Nourshargh, S., and Alon, R. (2014). Leukocyte migration into inflamed tissues. Immunity 41, 694-707. doi: 10.1016/j.immuni.2014.10.008

Okamoto, T., and Suzuki, K. (2017). The role of gap junction-mediated endothelial cell-cell interaction in the crosstalk between inflammation and blood coagulation. Int. J. Mol. Sci. 18:2254. doi: 10.3390/ijms18112254

Orellana, J. A., Velasquez, S., Williams, D. W., Saez, J. C., Berman, J. W., and Eugenin, E. A. (2013). Pannexin1 hemichannels are critical for HIV infection of human primary CD4+ T lymphocytes. J. Leukoc. Biol. 94, 399-407. doi: 10.1189/jlb.0512249

Oviedo-Orta, E., and Howard Evans, W. (2004). Gap junctions and connexinmediated communication in the immune system. Biochim. Biophys. Acta 1662, 102-112. doi: 10.1016/j.bbamem.2003.10.021

Oviedo-Orta, E., Hoy, T., and Evans, W. H. (2000). Intercellular communication in the immune system: differential expression of connexin 40 and 43 , and perturbation of gap junction channel functions in peripheral blood and tonsil human lymphocyte subpopulations. Immunology 99, 578-590. doi: 10.1046/j. 1365-2567.2000.00991.x

Pelegrin, P., and Surprenant, A. (2006). Pannexin-1 mediates large pore formation and interleukin-1beta release by the ATP-gated P2X7 receptor. EMBO J. 25, 5071-5082. doi: 10.1038/sj.emboj.7601378

Pepin, G., De Nardo, D., Rootes, C. L., Ullah, T. R., Al-Asmari, S. S., Balka, K. R., et al. (2020). Connexin-dependent transfer of cGAMP to phagocytes modulates antiviral responses. mBio 11:e3187-19. doi: 10.1128/mBio.03187-19

Poplimont, H., Georgantzoglou, A., Boulch, M., Walker, H. A., Coombs, C., Papaleonidopoulou, F., et al. (2020). Neutrophil swarming in damaged tissue is orchestrated by connexins and cooperative calcium alarm signals. Curr. Biol. 30, 2761-2776.e7. doi: 10.1016/j.cub.2020.05.030

Qin, X. H., Ma, X., Fang, S. F., Zhang, Z. Z., and Lu, J. M. (2019). IL-17 produced by Th17 cells alleviates the severity of fungal keratitis by suppressing CX43 expression in corneal peripheral vascular endothelial cells. Cell Cycle 18, 274-287. doi: 10.1080/15384101.2018.1556059

Robertson, J., Lang, S., Lambert, P. A., and Martin, P. E. (2010). Peptidoglycan derived from Staphylococcus epidermidis induces Connexin 43 hemichannel activity with consequences on the innate immune response in endothelial cells. Biochem. J. 432, 133-143. doi: 10.1042/BJ20091753

Sabroe, I., Dower, S. K., and Whyte, M. K. (2005). The role of Toll-like receptors in the regulation of neutrophil migration, activation, and apoptosis. Clin. Infect. Dis. 41(Suppl. 7), S421-S426. doi: 10.1086/431992

Saez, P. J., Vargas, P., Shoji, K. F., Harcha, P. A., Lennon-Dumenil, A. M., and Saez, J. C. (2017). ATP promotes the fast migration of dendritic cells through the activity of pannexin 1 channels and P2X7 receptors. Sci. Signal. 10:eaah7107. doi: 10.1126/scisignal.aah7107

Sarieddine, M. Z., Scheckenbach, K. E., Foglia, B., Maass, K., Garcia, I., Kwak, B. R., et al. (2009). Connexin 43 modulates neutrophil recruitment to the lung. J. Cell. Mol. Med. 13, 4560-4570. doi: 10.1111/j.1582-4934.2008.00654.x

Scheckenbach, K. E., Crespin, S., Kwak, B. R., and Chanson, M. (2011). Connexin channel-dependent signaling pathways in inflammation. J. Vasc. Res. 48, 91103. doi: $10.1159 / 000316942$

Schenk, U., Westendorf, A. M., Radaelli, E., Casati, A., Ferro, M., Fumagalli, M., et al. (2008). Purinergic control of T cell activation by ATP released through pannexin-1 hemichannels. Sci. Signal. 1:ra6. doi: 10.1126/scisignal.1160583

Sharma, A. K., Charles, E. J., Zhao, Y., Narahari, A. K., Baderdinni, P. K., Good, M. E., et al. (2018). Pannexin-1 channels on endothelial cells mediate vascular inflammation during lung ischemia-reperfusion injury. Am. J. Physiol. Lung Cell. Mol. Physiol. 315, L301-L312. doi: 10.1152/ajplung.00004.2018

Sohl, G., Maxeiner, S., and Willecke, K. (2005). Expression and functions of neuronal gap junctions. Nat. Rev. Neurosci. 6, 191-200. doi: 10.1038/nrn1627

Swayne, L. A., Johnstone, S. R., Ng, C. S., Sanchez-Arias, J. C., Good, M. E., Penuela, S., et al. (2020). Consideration of Pannexin 1 channels in COVID-19 pathology and treatment. Am. J. Physiol. Lung Cell. Mol. Physiol. 319, L121-L125. doi: 10.1152/ajplung.00146.2020

Tam, T. H., Chan, K. L., Boroumand, P., Liu, Z., Brozinick, J. T., Bui, H. H., et al. (2020). Nucleotides released from palmitate-activated murine macrophages attract neutrophils. J. Biol. Chem. 295, 4902-4911. doi: 10.1074/jbc.RA119. 010868

Thuringer, D., Berthenet, K., Cronier, L., Jego, G., Solary, E., and Garrido, C. (2015). Oncogenic extracellular HSP70 disrupts the gap-junctional coupling between capillary cells. Oncotarget 6, 10267-10283. doi: 10.18632/oncotarget.3522

Trautmann, A. (2009). Extracellular ATP in the immune system: more than just a "danger signal". Sci. Signal. 2:e6. doi: 10.1126/scisignal.256pe6

Valdebenito, S., Barreto, A., and Eugenin, E. A. (2018). The role of connexin and pannexin containing channels in the innate and acquired immune response. Biochim. Biophys. Acta Biomembr. 1860, 154-165. doi: 10.1016/j.bbamem.2017. 05.015

Valiunas, V., Brink, P. R., and White, T. W. (2019). Lens connexin channels have differential permeability to the second messenger cAMP. Invest. Ophthalmol. Vis. Sci. 60, 3821-3829. doi: 10.1167/iovs.19-27302

Veliz, L. P., Gonzalez, F. G., Duling, B. R., Saez, J. C., and Boric, M. P. (2008). Functional role of gap junctions in cytokine-induced leukocyte adhesion to endothelium in vivo. Am. J. Physiol. Heart Circ. Physiol. 295, H1056-H1066. doi: 10.1152/ajpheart.00266.2008

Wang, X., and Chen, D. (2018). Purinergic regulation of neutrophil function. Front. Immunol. 9:399. doi: 10.3389/fimmu.2018.00399

Wang, X., Qin, W., Xu, X., Xiong, Y., Zhang, Y., Zhang, H., et al. (2017). Endotoxin-induced autocrine ATP signaling inhibits neutrophil chemotaxis through enhancing myosin light chain phosphorylation. Proc. Natl. Acad. Sci. U.S.A. 114, 4483-4488. doi: 10.1073/pnas.1616752114

Wei, R., Wang, J., Xu, Y., Yin, B., He, F., Du, Y., et al. (2015). Probenecid protects against cerebral ischemia/reperfusion injury by inhibiting lysosomal and inflammatory damage in rats. Neuroscience 301, 168-177. doi: 10.1016/j. neuroscience.2015.05.070

Willebrords, J., Crespo Yanguas, S., Maes, M., Decrock, E., Wang, N., Leybaert, L., et al. (2016). Connexins and their channels in inflammation. Crit. Rev. Biochem. Mol. Biol. 51, 413-439. doi: 10.1080/10409238.2016.1204980

Willebrords, J., Maes, M., Crespo Yanguas, S., and Vinken, M. (2017). Inhibitors of connexin and pannexin channels as potential therapeutics. Pharmacol. Ther. 180, 144-160. doi: 10.1016/j.pharmthera.2017.07.001

Woehrle, T., Yip, L., Elkhal, A., Sumi, Y., Chen, Y., Yao, Y., et al. (2010). Pannexin1 hemichannel-mediated ATP release together with P2X1 and P2X4 receptors regulate T-cell activation at the immune synapse. Blood 116, 3475-3484. doi: 10.1182/blood-2010-04-277707

Yang, Y., Delalio, L. J., Best, A. K., Macal, E., Milstein, J., Donnelly, I., et al. (2020). Endothelial Pannexin 1 channels control inflammation by regulating intracellular calcium. J. Immunol. 204, 2995-3007. doi: 10.4049/jimmunol. 1901089

Zahler, S., Hoffmann, A., Gloe, T., and Pohl, U. (2003). Gap-junctional coupling between neutrophils and endothelial cells: a novel modulator of transendothelial migration. J. Leukoc. Biol. 73, 118-126. doi: 10.1189/jlb. 0402184

Zhang, H. C., Zhang, Z. S., Zhang, L., Wang, A., Zhu, H., Li, L., et al. (2018). Connexin 43 in splenic lymphocytes is involved in the regulation of $\mathrm{CD} 4+\mathrm{CD} 25+\mathrm{T}$ lymphocyte proliferation and cytokine production in hypertensive inflammation. Int. J. Mol. Med. 41, 13-24. doi: 10.3892/ijmm.2017. 3201

Zhou, K. Q., Green, C. R., Bennet, L., Gunn, A. J., and Davidson, J. O. (2019). The role of connexin and pannexin channels in perinatal brain injury and inflammation. Front. Physiol. 10:141. doi: 10.3389/fphys.2019.00141

Conflict of Interest: The authors declare that the research was conducted in the absence of any commercial or financial relationships that could be construed as a potential conflict of interest.

Copyright $(2020$ Kameritsch and Pogoda. This is an open-access article distributed under the terms of the Creative Commons Attribution License (CC BY). The use, distribution or reproduction in other forums is permitted, provided the original author(s) and the copyright owner(s) are credited and that the original publication in this journal is cited, in accordance with accepted academic practice. No use, distribution or reproduction is permitted which does not comply with these terms. 